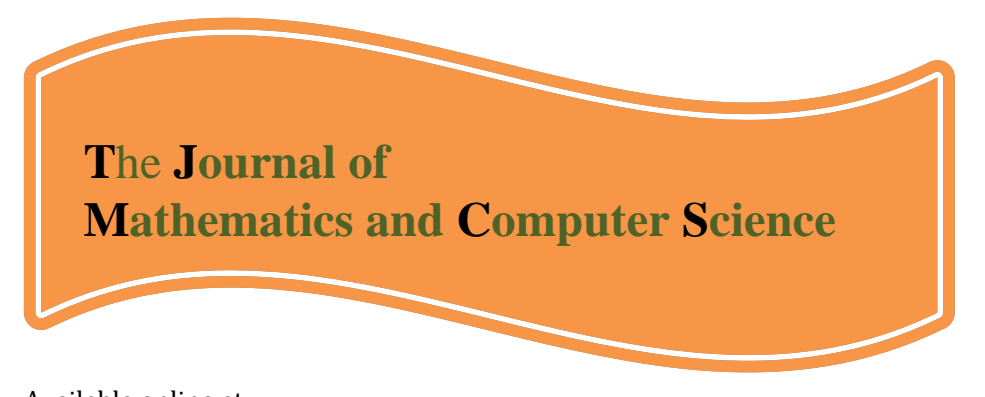

Available online at

http://www.TIMCS.com

The Journal of Mathematics and Computer Science Vol .2 No.2 (2011) 241-254

\title{
The Estimation of Transference Rate HIV Infection into AIDS and Mortality in Children by Fuzzy Control
}

\author{
Ali Vahidian Kamyad ${ }^{1,}$, Mojtaba shokohi nia ${ }^{2}$, Mohammmad reza shokohi nia 3 \\ Professor Department of Mathematical Sciences, Ferdowsi University of Mashhad, kamyad@math.um.ac.ir \\ Islamic Azad University, Damghan Branch, Iran , Mshokohinia2020@yahoo.com \\ Mashhad Education Department District 2,Iran, Mshokoohinia@yahoo.com
}

Received: August 2010, Revised: November 2010

Online Publication: January 2011

\begin{abstract}
Mathematical study of epidemic diseases is done for evaluation and control of diseases.certain and classis model of mathematics that describe this phenomenons frequently can not peruse all aspects for effect the model, because human biengs have different physiologic properties and circumstance.then they can not be perused as a same organism, then we shold tent to models that consider all aspect for survey of disease process with real and practical conditions. Rally this theory to disease can model with fuzzy mathematic.Over the last decade, the mathematical literature on uncertainty and fuzziness has grown considerably in system modeling, optimization, control in medical sciences.and several authors have advocated the use of fuzzy set theory in epidemiology diseases.Since the advent of the HIV infection, several mathematical models have been developed to describe its dynamics but that models has been perused with certain mathematic.In this paper we suggest fuzzy set theory, to estimation of transference rate of positive HIV population to AIDS (acquired immunodeficiency syndrome) in children manifestation And Estimation Rate Death In Children Using fuzzy control. Clinical
\end{abstract}

\footnotetext{
1,* Corresponding author: Mojtaba shokohi nia

${ }^{2}$ Position and Special field of the second author

${ }^{3}$ Position and Special field of the second author
} 
examination of physicians confirm that transference rate of positive HIV population to AIDS is not certain and remarkably depend to essential factors like CD4 lymphosite cells count and viral load count and age of infected individual.in this research the transferens rate of positive HIV population to AIDS in children and And Estimation Rate Death In Children has estimated as a function of CD4 lymphosite cells count and viral load count and age of infected individual.After solve the model, with our algorithm ,the result corroborate the clinical real methical data with good access.

Keywords: Fuzzy control ، CD4+ T lymphosite ‘HIV Infection.

\section{Introduction}

Although 1400 children with the ages lower than 15 years die due to the diseases related to AIDS every day, more than 6000 adolescents with the ages 15-24 years are infected to HIV every day. In $2007,45 \%$ of the new infected individuals with HIV are within this age group. 15 million children have lost their patients because of AIDS. The children infected with HIV have been mostly affected during fetal period or at birth; indeed, their mothers have conveyed their disease to them. Most of the children with HIV infection seem normal at birth. In general, the incubation period of AIDS in children is much shorter than in adults. The researchers of the control center of diseases have presented 3 general patterns for this disease in children.

1.Rapid developers: The symptoms related to AIDS appear in this group which include $25 \%$ of the cases during their first six months of life.

2.Slow developers: The symptoms related to AIDS appear in this group which include $70 \%$ of the cases during their six-month to 3 years of age.

3.Adult developers: The symptoms related to AIDS appear in these three group which include less than $5 \%$ of the cases during their 3-10 years of age. [10]

As it is reflected explicitly in this classification, the symptoms related to AIDS are shown in most of the children with HIV infection within 3 years. The incident is in contrast to this in the adults among whom the AIDS incubation period lasts 7-10 years. The statistics has estimated the average age of one year as the onset of AIDS symptoms in children. In suckling infants with the symptoms related to AIDS in their first year of life, the average age of the onset of symptoms has been 5 months.[6]

\section{Viruses and the Response of Immunity System}

The most important part of the immunity system that is invaded and suffered from HIV directly is CD4+T lymphocytes. In 1984, it was found that the main target of HIV is T cells with CD4 receptor, i.e., CD4+T. In other words, CD4 receptor is necessary for entering HIV into a cell.

This type of infection may fight with the response of the immunity system again and hurt its main part, i.e. CD4+T cells. The main target of HIV infection is CD4+T cells as a result of which these cells die; therefore, no CD4+T cell give significant assistance to antibody responses. During this process, the immunity system becomes weaker and can not overcome the infection. The mechanism that viruses hurt the

$\mathrm{CD} 4+\mathrm{T}$ cells is unknown.[7]. 


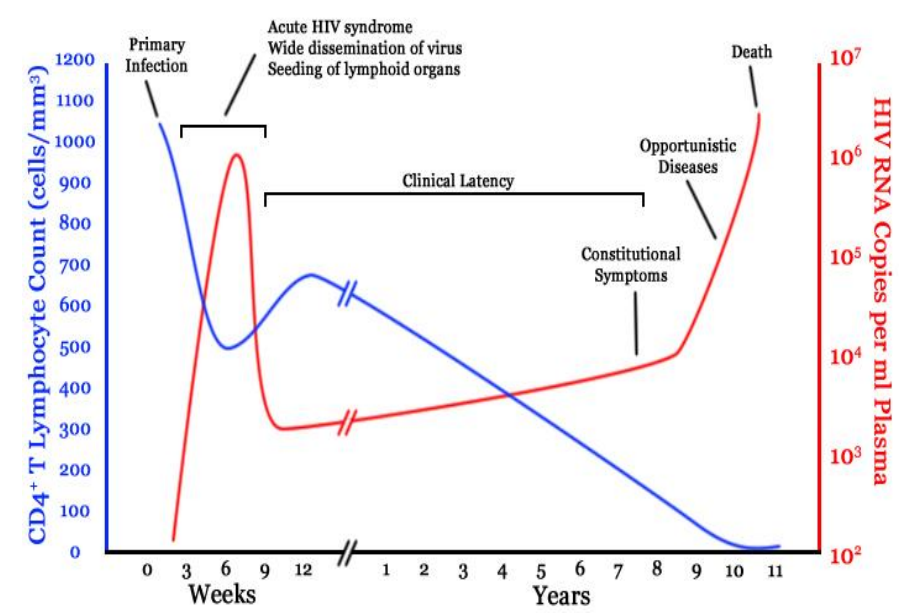

Figure 1 shows the HIV infection in three stages

In the acute stage, the viral load increases up to a higher level following which the specific response of the immunity system against HIV is given and the viral load decreases. This mode indicates the onset stage of the disease with no symptom. In this stage, the viral load increases a little and the number of $\mathrm{CD} 4+\mathrm{T}$ and the specific response of the immunity system remain approximately in a stable level. After a while, the viral load increases rapidly subsequent to which the number of CD4+Ts and the response of immunity system decrease. This mode indicates the incidence of AIDS phenomenon in patients.

\section{The Number of CD4+T Lymphocytes in Different Ages of Childhood}

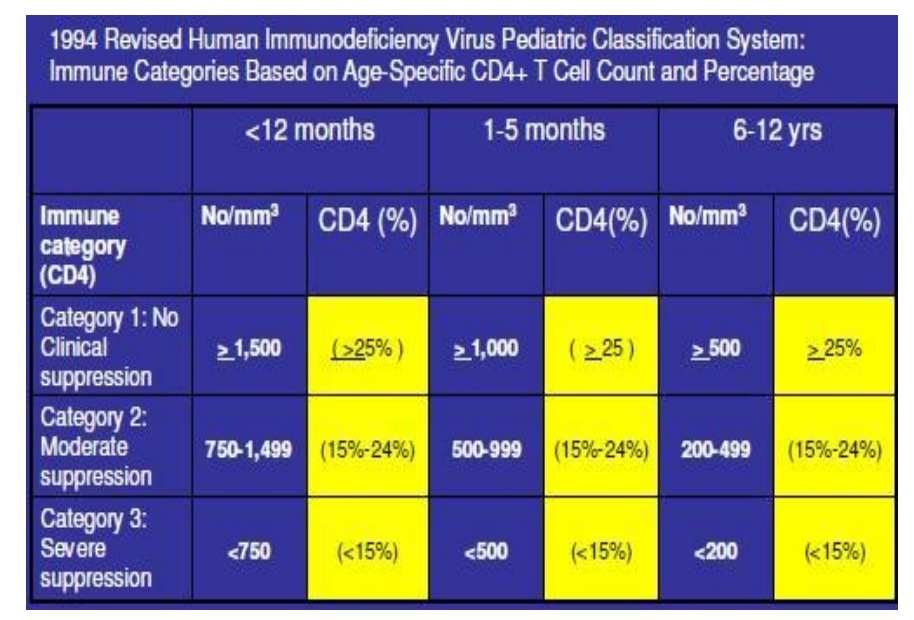

Of course, considering the variability of absolute count of CD4+T cells, it is better to pay attention to the percentage of these cells.[11]

\section{Intelligent Controllers of Fuzzy Logic}

Fuzzy logic was emerged by Dr.Lotfizadeh through publishing the article entitled "Fuzzy Sets". The concepts and various aspects of fuzzy logic have been studied and surveyed deeply by the mathematicians, scientists, and engineers throughout the world since 1965 up to now.[1]

The theory of fuzzy sets indicates a concept of uncertainty. In general, the theory of probabilities is the first tool for analyzing uncertainty and it is assumed that uncertainty is a stochastic process. But all the uncertainties are not stochastic and the theory of fuzzy sets is used for modeling a part of uncertainty which is associated with negligence, ambiguity, and insufficiency of information. The theory of sets considers a difference between the ones that are the members of a set and those which are not. The most essential principle of fuzzy set is the fact that the membership function $U$ can have values between zero and one.

The general structure of the logic fuzzy controllers is illustrated in Figure 2[2]. 


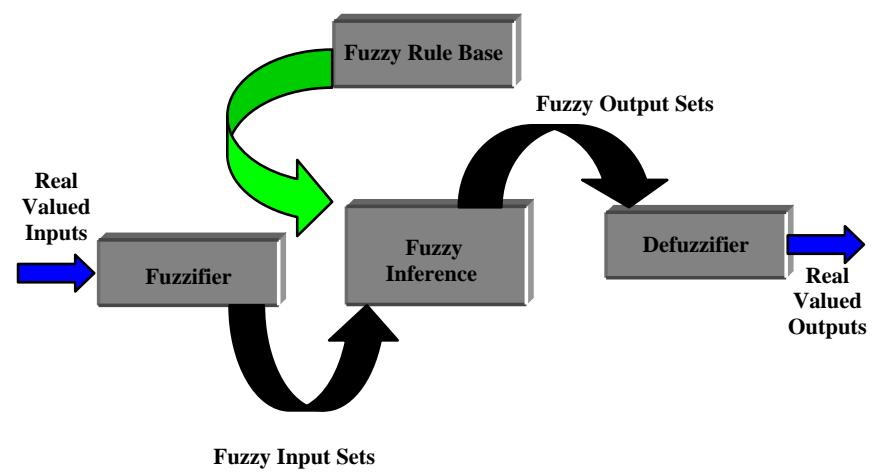

Figure 2. The general structure of the logic fuzzy controller

The process of making fuzzy: Making fuzzy is a process in which the inputs of fuzzy control are illustrated in lieu of their membership in fuzzy functions.

The basis of the fuzzy control attitude is the basic fuzzy rules which are in the form of if.....then. The base of fuzzy rules includes a set of language rules that are extractable from any of the following

sources with the experts' information:

- The physical rules governing the dynamic equations of the system

- Data from the available controllers

- Experimental knowledge from the expert and skillful individuals.

If the knowledge of the expert is used; then there is no need to mathematical model of the system and this is one of the great advantages of fuzzy systems. The rules are usually displayed in tables.

In the present paper, while having the percentage of the number of CD4 cells and age of the child infected with HIV, our objective is to estimate the rate of changing HIV infection into AIDS as well as the probability of child mortality in such a way that are in conformity with the realities; by the controllers with Sugeno approach.[2].

\section{Modeling the rate of changing HIV infection into AIDS in the children on the basis of two inputs including CD4 and the age of the infected child.}

In this case, for the percentage of the number of CD4 cells, language variables including very low, low, medium, high, very high and for the ages of the children, the language variables such as chick, infant, child, and adolescent have been considered.

According to the medial data, on the basis of the number of CD4 cells and ages of children, the language rules have been specified in fuzzy sets as follows: 


Very high
High
Medium
Low
Very low

Very high

Medium

Very low

$$
\begin{aligned}
30 \% & >\mathrm{CD} 4 \sim>20 \% \\
25 \% & >\mathrm{CD} 4 \sim>15 \% \\
20 \% \sim>\mathrm{CD} 4 \sim>10 \% & >10 \% \\
15 \% & >\mathrm{CD} 4 \sim>5 \% \\
15 \% & >\mathrm{CD} 4 \sim>5 \%
\end{aligned}
$$

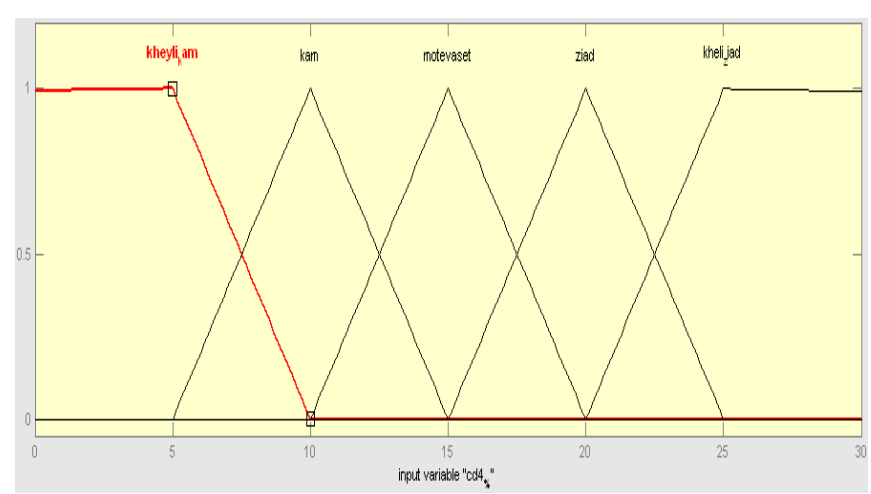

Figure 3. The functions of fuzzy membership related to the percentage of the number of CD4 cells of the child infected with HIV.

The ages of the children are also illustrated with fuzzy sets as follows:

Chick

infant

child adolescent

$$
\begin{aligned}
& \text { age }<\sim 1 \text { (year } \\
& 0.6 \text { (months) }<\sim \text { age }<\sim 3.5 \text { (year) } \\
& 3 \text { (year) < age < } 7.5 \text { (year) } \\
& 7 \text { (year) < age < 10(year) }
\end{aligned}
$$

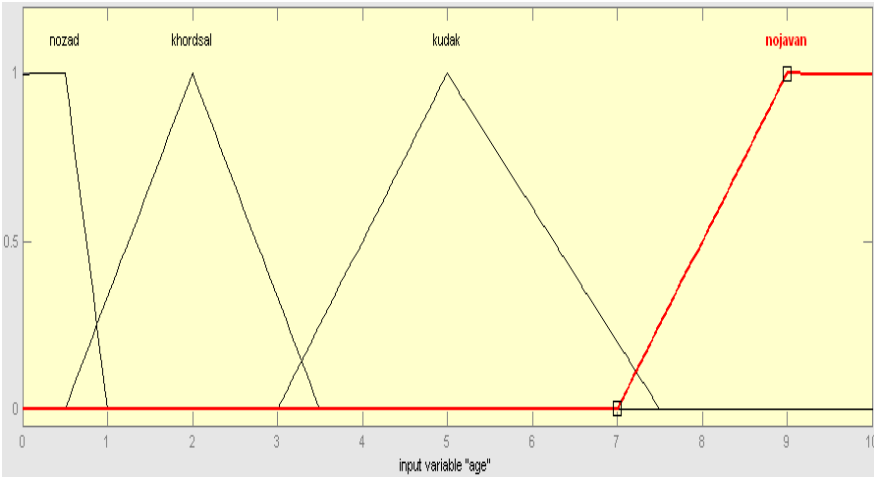

Figure 4. The functions of fuzzy membership related to the age of the child infected with HIV.

\section{Definition of the fuzzy rule base for two inputs (age and the number of CD4 cells) and the output of the percentage of being infected with AIDS.}

Considering the procedure of allocating language variables to the percentage of the number of CD4 cells and the age of the infected child, we will have 20 rules as follows:

Rule 1. If the patient is a chick and the percentage of CD4 is very low, then the rate of infection with AIDS is very very high.

Rule 2. If the patient is a chick and the percentage of CD4 is low, then the rate of infection with AIDS is very high.

Rule 3. If the patient is a chick and the percentage of CD4 is medium, then the rate of infection with AIDS is high. 
Rule 4. If the patient is a chick and the percentage of CD4 is high, then the rate of infection with AIDS is medium.

Rule 5. If the patient is a chick and the percentage of CD4 is very high, then the rate of infection with AIDS is low.

Rule 6. If the patient is a infant and the percentage of CD4 is very low, then the rate of infection with AIDS is very very high.

Rule 7. If the patient is a infant and the percentage of CD4 is low, then the rate of infection with AIDS is very high.

Rule 8. If the patient is a infant and the percentage of CD4 is medium, then the rate of infection with AIDS is high.

Rule 9. If the patient is a infant and the percentage of CD4 is high, then the rate of infection with AIDS is very medium.

Rule 10. If the patient is a infant and the percentage of CD4 is very high, then the rate of infection with AIDS is low.

Rule 11. If the patient is a child and the percentage of CD4 is very low, then the rate of infection with AIDS is very high.

Rule 12. If the patient is a child and the percentage of CD4 is low, then the rate of infection with AIDS is high.

Rule 13. If the patient is a child and the percentage of CD4 is medium, then the rate of infection with AIDS is medium.

Rule 14. If the patient is a child and the percentage of CD4 is high, then the rate of infection with AIDS is low.

Rule 15. If the patient is a child and the percentage of CD4 is very high, then the rate of infection with AIDS is very low.

Rule 16. If the patient is a adolescent and the percentage of CD4 is very low, then the rate of infection with AIDS is high.

Rule 17. If the patient is a adolescent and the percentage of CD4 is low, then the rate of infection with AIDS is medium.

Rule 18. If the patient is a adolescent and the percentage of CD4 is medium, then the rate of infection with AIDS is low.

Rule 19. If the patient is a adolescent and the percentage of CD4 is high, then the rate of infection with AIDS is very low.

Rule 20. If the patient is a adolescent and the percentage of CD4 is very high, then the rate of infection with AIDS is very very low.

\section{Calculation of the rate of changing HIV infection to AIDS in children on the basis of the fuzzy inference motor.}

The medical clinical studies have shown that the rate of changing infection with HIV into AIDS or the mortality probability of the child is not a certain number and there is an uncertainty in this regard, i.e., it is possible that the numbers of CD4 cells and the ages of two patients are the same, but the percentage of their infection with AIDS is different. The rate of changing the infection into AIDS is significantly dependent on the number of CD4 cells and the age of the infected child. Therefore, the output of the system which is the rate of changing infection to AIDS is estimated from the Fuzzy Rules which have been designed on the individual's information by Sugeno approach. According to the medical data, there is no accurate formula for obtaining the rate of changing infection into AIDS on the basis of the number of CD4 cells and the age of the infected child because all data have fuzzy ambiguity and humans are not the same system and are different from genetic, environment, nutrition, mental conditions,....points of view. Having an approximate amplitude for the for the number of CD4 cells and the age of the infected child, a range of the rate of changing infection into AIDS is estimated[4].

The functions of fuzzy membership associated with the probability of infection with AIDS for the child infected to HIV are considered as follows: 
A. Vahidian Kamyad, M. shokohi nia, M. R. shokohi nia/ TJMCS Vol .2 No.2 (2011) 241-254

Very very low
Very low
Low
Medium
High
Very high
Very very high

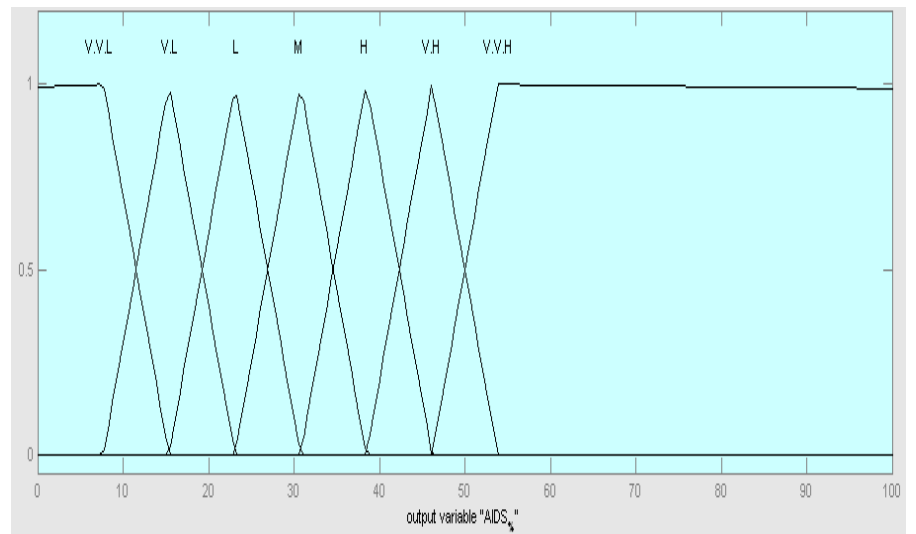

AIDS $<\sim 15 \%$

$7 \%<$ AIDS $<\sim 23 \%$

$15 \%<\sim$ AIDS $<\sim 31 \%$

$23 \%<\sim$ AIDS $<\sim 39 \%$

$31 \%<\sim$ AIDS $<\sim 47 \%$

$39 \%<\sim$ AIDS $<\sim 54 \%$

$47 \%<\sim$ AIDS

Figure 5. The functions of membership related to the rate of infection with AIDS for the child infected to HIV

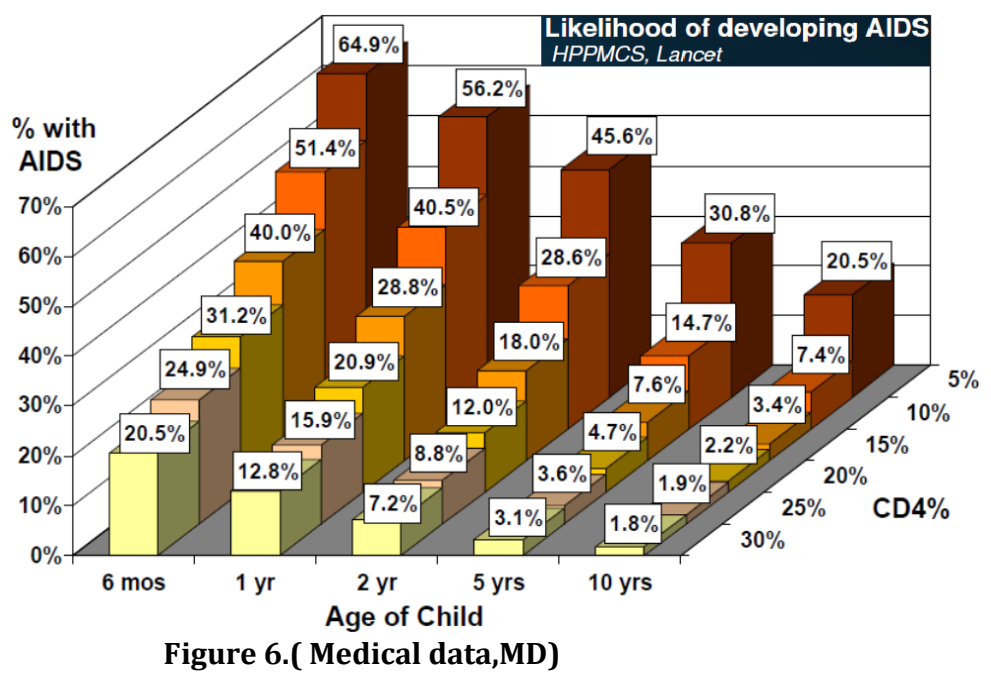

These data have been presented by the specialist from the famous scientific Journal named Lancet.

\section{Modeling the estimation of the mortality percentage in children infected with HIV(mathematical linear function on the basis of two variables of CD4 and age for the output fuzzy rules)}

No acceptable response is given by the functions of membership associated with the rate of infection to AIDS for estimating the mortality percentage in children with HIV, therefore, it is sufficient to increase the number of fuzzy sets in proportion to the data so that better results are obtained. Therefore, the new membership functions for estimating the mortality percentage in children with HIV is as follows: 
A. Vahidian Kamyad, M. shokohi nia, M. R. shokohi nia/ TJMCS Vol .2 No.2 (2011) 241-254

Very very very low

Very very low

Very low

Low

Medium

High

Very high

Very very high

Very very very high death $<\sim 20 \%$

$10 \%<\sim$ death $<\sim 30 \%$

$20 \%<\sim$ death $<\sim 40 \%$

$30 \%<\sim$ death $<\sim 50 \%$

$40 \%<\sim$ death $<\sim 60 \%$

$50 \%<\sim$ death $<\sim 70 \%$

$60 \%<\sim$ death $<\sim 80 \%$

$70 \%<\sim$ death $<\sim 90 \%$

$80 \%<\sim$ death

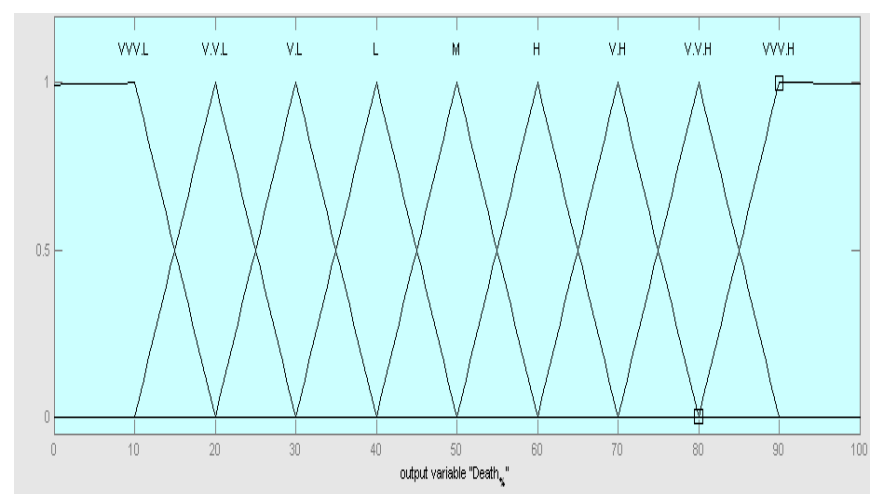

Figure 7. The membership functions for estimating the mortality percentage in children with HIV

Considering the procedure of allocating language variables to the percentage of the number of CD4 cells and the age of the infected child, we will have 36 rules.

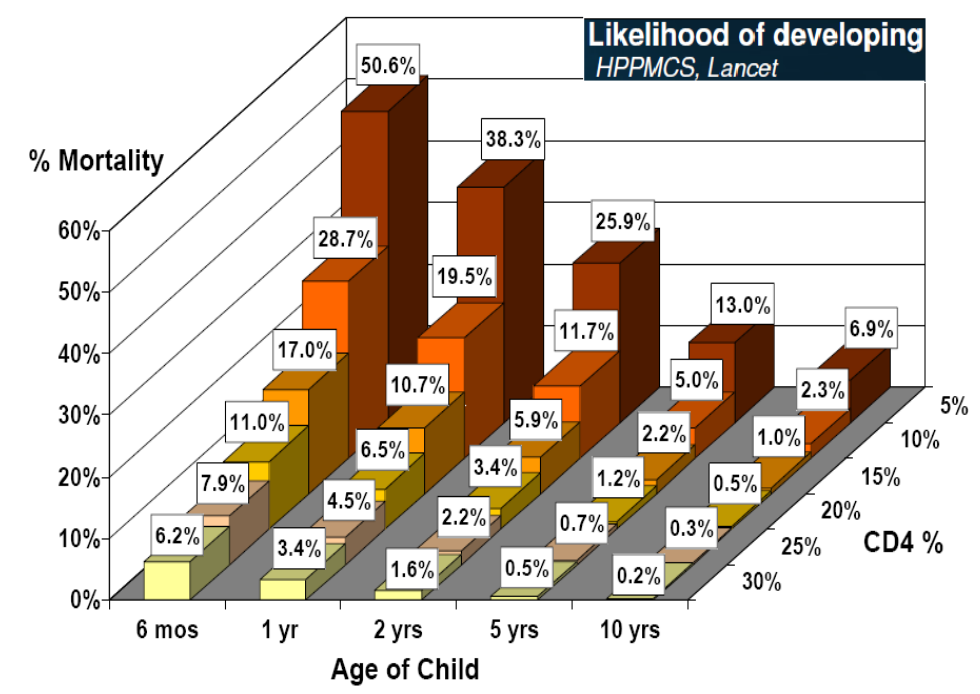

Figure 8.( Medical data,MD) 
9. The results obtained from the approach Sugeno for estimating the rate of being infected to AIDS in children with HIV:
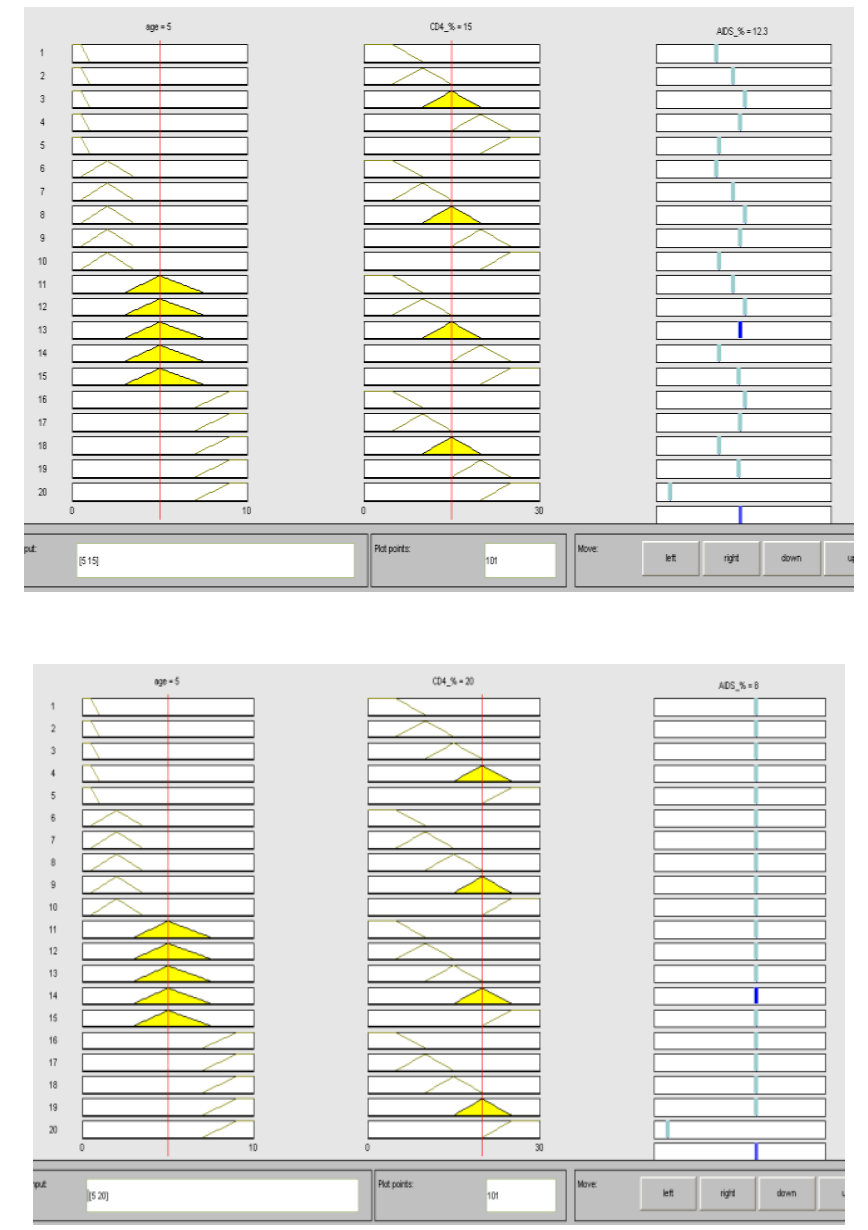

10. The results obtained from the approach Sugeno for estimating the mortality percentage in children with HIV:

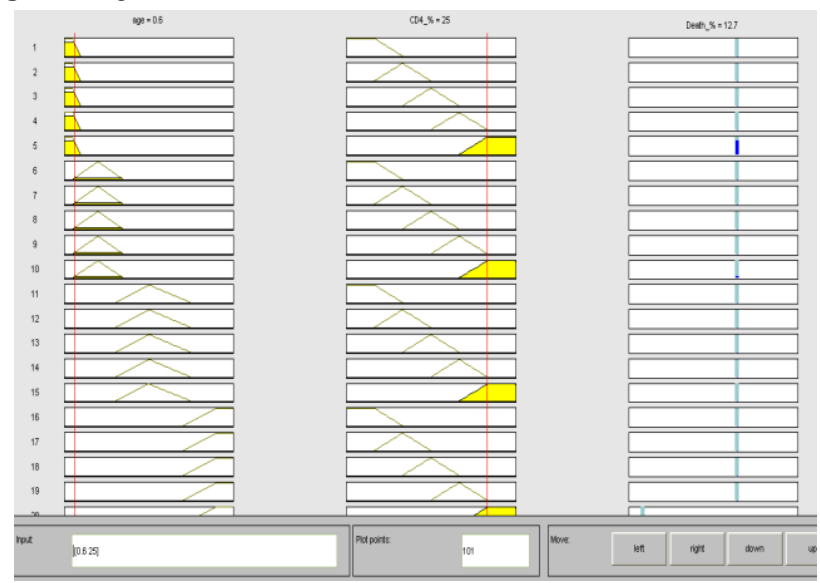




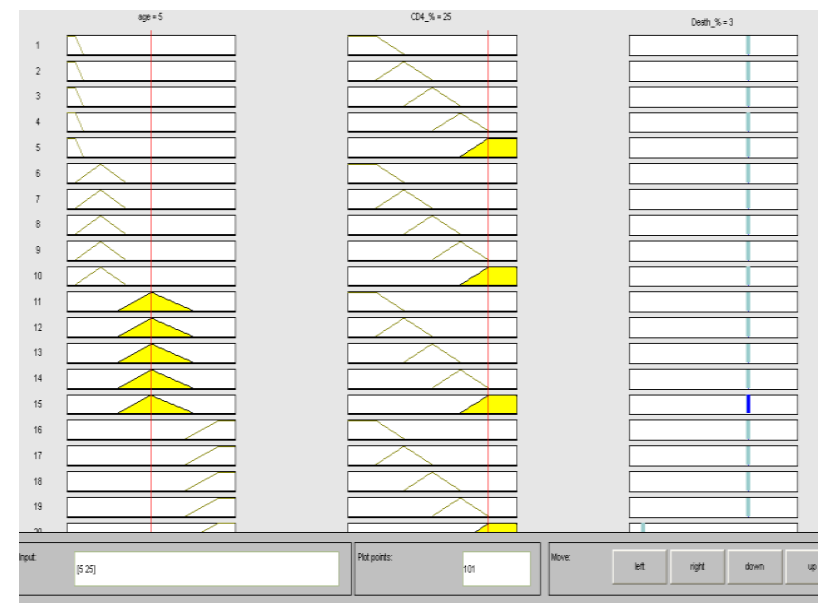

\section{Comparing the known medical data and the results obtained on the basis of the quadratic functions by fuzzy control method and Sugeno approach.}

The mortality percentage in children with HIV on the basis of the CD4 cells and the ages of the infected children.

We assume the number of CD4 lymphocytes in any stage constant and compare them.

For example, for CD4 in lieu of 30\%, we have:

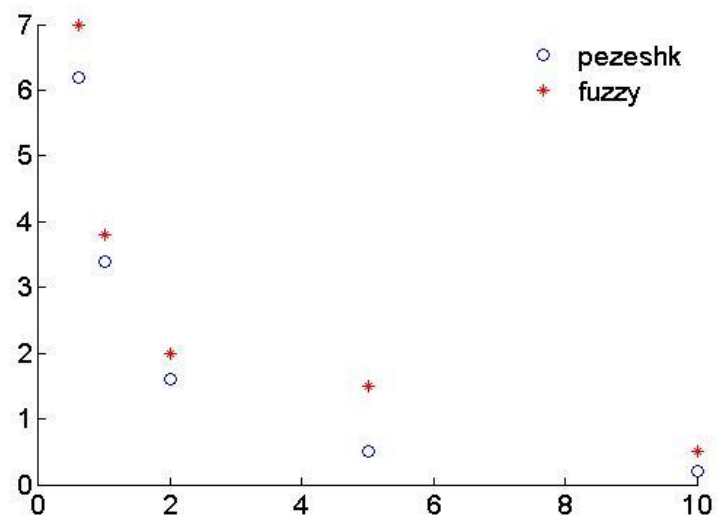

It should be noted that in this diagram, pezeshk is the medial data (MD) and fuzzy means the results obtained by Sugeno inference motor of fuzzy control.

Table 1.

\begin{tabular}{|c|c|c|c|}
\hline Patient number & $\begin{array}{c}\text { Age of the child } \\
\text { with HIV }\end{array}$ & $\begin{array}{c}\text { Mortality percentage } \\
\text { in children obtained } \\
\text { by known medical } \\
\text { data }\end{array}$ & $\begin{array}{c}\text { Mortality percentage } \\
\text { in children on the } \\
\text { basis of the quadratic } \\
\text { function by fuzzy } \\
\text { control }\end{array}$ \\
\hline 1 & 0.6 & 6.2 & 7 \\
\hline 2 & 1 & 3.4 & 3.8 \\
\hline 3 & 2 & 1.6 & 1.5 \\
\hline 4 & 5 & 0.5 & 0.5 \\
\hline 5 & 10 & 0.2 & \\
\hline
\end{tabular}

Quadratic regression equations gained on the basis of two series of data:

1. with the aid of medical data

2. with the aid of data obtained from the results of fuzzy control. 


$$
\begin{aligned}
& Y=0.1333 X^{2}-1.8962 X+5.9589 \quad \text { aid of medical data } \\
& Y=0.1146 X^{2}-1.7163 X+6.3556 \quad \text { aid of fuzzy control }
\end{aligned}
$$

Also for CD4 in lieu of 15\%, we have:

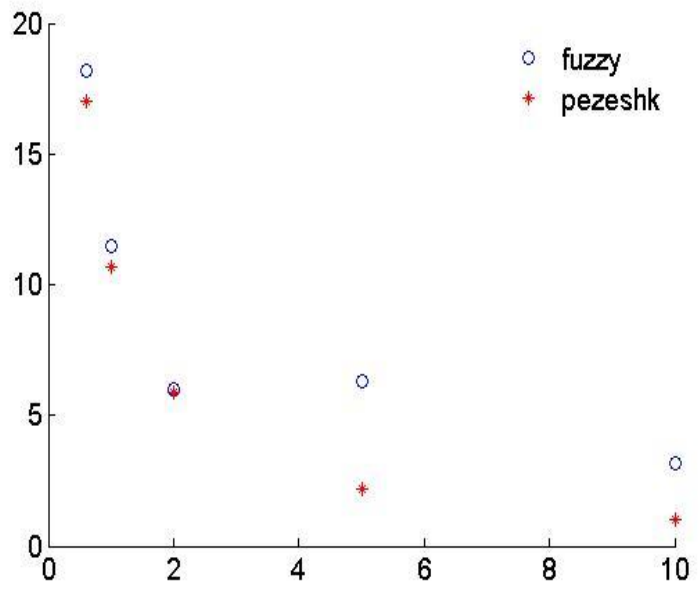

Table 2.

\begin{tabular}{|c|c|c|c|}
\hline Patient number & $\begin{array}{c}\text { Age of the child with } \\
\text { HIV }\end{array}$ & $\begin{array}{c}\text { Mortality percentage } \\
\text { in children obtained } \\
\text { by known medical } \\
\text { data }\end{array}$ & $\begin{array}{c}\text { Mortality percentage } \\
\text { in children on the } \\
\text { basis of the } \\
\text { quadratic function } \\
\text { by fuzzy control }\end{array}$ \\
\hline 1 & 0.6 & 17 & 18.2 \\
\hline 2 & 1 & 10.7 & 11.5 \\
\hline 3 & 2 & 5.9 & 6 \\
\hline 4 & 5 & 2.2 & 6.28 \\
\hline 5 & 10 & 1 & 3.6 \\
\hline
\end{tabular}

Quadratic regression equations gained on the basis of two series of data:

1. with the aid of medical data

2. with the aid of data obtained from the results of fuzzy control.

$$
\begin{aligned}
& Y=0.3387 X^{2}-4.9553 X+16.9632 \quad \text { aid of medical data } \\
& Y=0.2469 X^{2}-3.7692 X+16.6203 \quad \text { aid of fuzzy control }
\end{aligned}
$$

\section{The percentage of being infected to AIDS in children with HIV on the basis of CD4 cells and the ages of infected children .}

We assume the number of CD4 lymphocytes in any stage constant and compare them.

For example, for CD4 in lieu of $25 \%$, we have: 


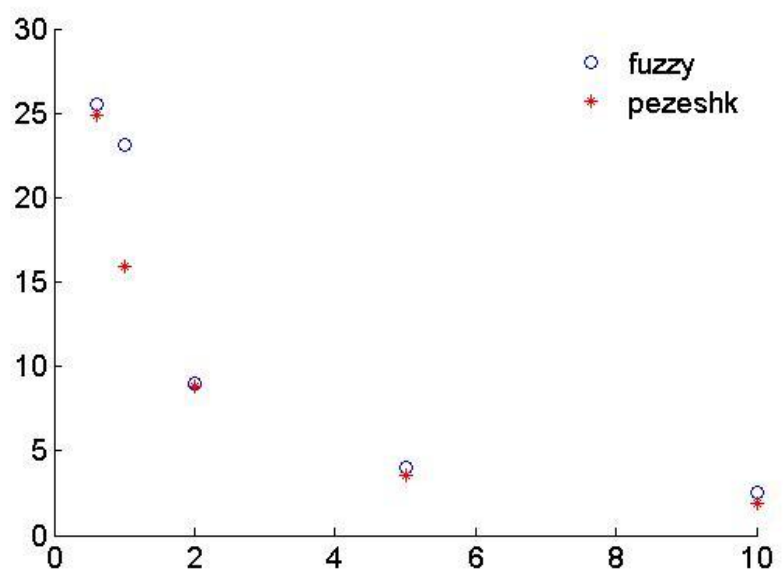

Table 3.

\begin{tabular}{|c|c|r|r|}
\hline Patient number & $\begin{array}{r}\text { Age of the child } \\
\text { with HIV }\end{array}$ & $\begin{array}{r}\text { Mortality } \\
\text { percentage in } \\
\text { children obtained } \\
\text { by known medical } \\
\text { data }\end{array}$ & $\begin{array}{r}\text { Mortality } \\
\text { percentage in } \\
\text { children on the } \\
\text { basis of the } \\
\text { quadratic function } \\
\text { by fuzzy control }\end{array}$ \\
\hline 1 & 0.6 & 24.9 & 25.5 \\
\hline 2 & 1 & 15.9 & 23.1 \\
\hline 3 & 2 & 8.8 & 9 \\
\hline 4 & 5 & 3.6 & 4 \\
\hline 5 & 10 & 1.9 & 2.5 \\
\hline
\end{tabular}

Quadratic regression equations gained on the basis of two series of data:

2. with the aid of data obtained from the results of fuzzy control.

1. with the aid of medical data

$$
\begin{array}{lr}
Y=0.4901 X^{2}-7.1563 X+24.8638 & \text { aid of medical data } \\
Y=0.5741 X^{2}-8.3346 X+28.8564 & \text { aid of fuzzy control }
\end{array}
$$

Also, for CD4 in lieu of $10 \%$, we have:

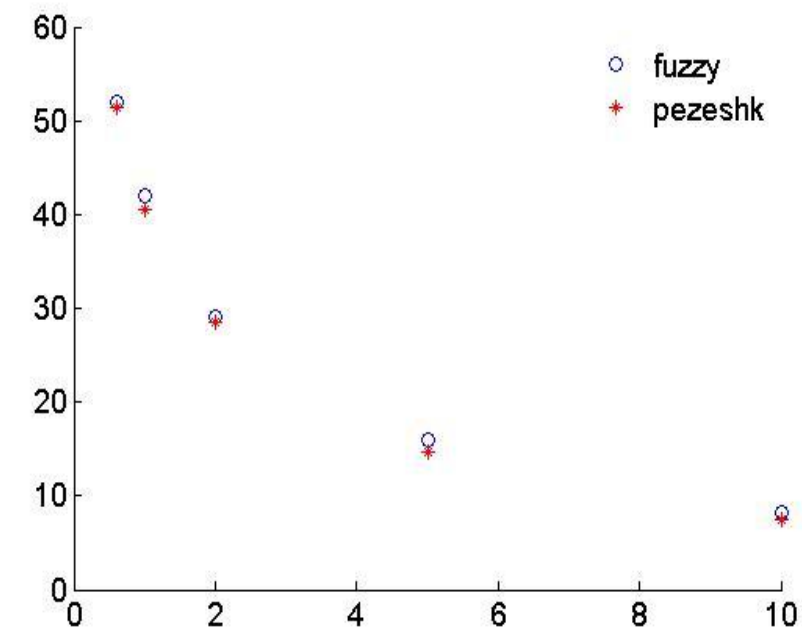


Table 4.

\begin{tabular}{|c|c|l|l|}
\hline Patient number & $\begin{array}{l}\text { Age of the child } \\
\text { with HIV }\end{array}$ & $\begin{array}{l}\text { Mortality } \\
\text { percentage in } \\
\text { children obtained } \\
\text { by known medical } \\
\text { data }\end{array}$ & $\begin{array}{l}\text { Mortality } \\
\text { percentage in } \\
\text { children on the } \\
\text { basis of the } \\
\text { quadratic function } \\
\text { by fuzzy control }\end{array}$ \\
\hline 1 & 0.6 & 51.4 & 52 \\
\hline 2 & 1 & 40.5 & 42.3 \\
\hline 3 & 2 & 28.6 & 29 \\
\hline 4 & 5 & 14.7 & 8.2 \\
\hline 5 & 10 & 7.4 & 16 \\
\hline
\end{tabular}

Quadratic regression equations gained on the basis of two series of data:

1. with the aid of medical data

2. with the aid of data obtained from the results of fuzzy control.

$\mathrm{Y}=0.7503 \mathrm{X}^{2}-12.1232 \mathrm{X}+54.0578$

aid of medical data

$\mathrm{Y}=0.7371 \mathrm{X}^{2}-11.9828 \mathrm{X}+54.7984$

aid of fuzzy control

\section{Conclusion}

In this paper, we used the theory of fuzzy sets for estimating the rate of changing HIV infection to AIDS in children and the mortality percentage in children with HIV. The rate of changing HIV infection into AIDS in children and the mortality percentage in infected children were estimated as a function of the number of CD4 cells and ages of the infected children.

It is seen that the designed controllers give desirable and acceptable responses. The clinical data confirm the responses given by this method after doing calculations which is fully optimal from the medical point of view. As it is shown in this paper, the control method based on fuzzy logic has the potential of using the experts' knowledge in curing diseases including AIDS.

\section{References}

[1] Li-Xing-Wang, A Course in Fuzzy Systems and Control,1996

[2] Ali vahidian kamyad,hamed tareghian,

an introduction to fuzzy logic for practical application,2002

[3] Sugeno and Nishida,M. 1985, "Fuzzy control of model car" Fss 16,(103-113).

[4] Sugeno, M. 1985.b“An introductory survey of Fuzzy control” Inform Sci, 36 (59-83).

[5] Predictive value of absolute CD4 cell count for disease progression in untreated HIV-1infected children

HIV Paediatric Prognostic Markers Collaborative Study 2006, 20:1289-1294

[6] Wachsler-Felder, Charles J. Golden 28 Neuropsychological consequences of HIV in children A review of current literature

2000"

[7] Magnhild Eide 
A. Vahidian Kamyad, M. shokohi nia, M. R. shokohi nia/ TJMCS Vol .2 No.2 (2011) 241-254

Social consequences of HIV-positive women's participation in prevention of mother-to-child transmission programmes

2004"

[8] Alfredo Guarino, *Maria Immacolata

Effects of Nutritional Rehabilitation on Intestinal Function and on CD4 Cell Number in Children With HIV

2002

[9] LucileÂia Teixeiraa, Hernan Valdeza, Poor CD4 T cell restoration after suppression of HIV-1 replication may re-ect lower thymic function

AIDS 2001, 15:1749

[10] Wafaie W. Fawzia,b,Gernar d I.,Donna Spiegelmanb, Randomized trial of vitamin supplements in relation to transmission of HIV-1 through breastfeeding and early child mortality

AIDS 2002, 16:1935-1944

[11] Akihiko Saitoh, MD, a* Kumud K. Singh, PhD, Association of CD41 T-lymphocyte counts and new thymic emigrants in HIV-infected children during successful highly active antiretroviral therapy

2006;117:909-15

[12] Mandell GL, Bennett JE, Dolin R. Principles and Practice of Infectious Disease,2000 